\title{
Article \\ Traits versus Grades-The Incremental Predictive Power of Positive Psychological Factors over Pre-Enrollment Achievement Measures on Academic Performance
}

\author{
Beatrix Séllei $^{1, *}$, Nóra Stumphauser ${ }^{1}$ and Roland Molontay ${ }^{1,2}$ (D) \\ 1 Department of Ergonomics and Psychology, Budapest University of Technology and Economics, \\ Magyar Tudósok Körútja 2, 1111 Budapest, Hungary; nora.stumphauser@edu.bme.hu (N.S.); \\ molontay@math.bme.hu (R.M.) \\ 2 MTA-BME Stochastics Research Group, 1111 Budapest, Hungary \\ * Correspondence: sellei.beatrix@gtk.bme.hu
}

\section{check for} updates

Citation: Séllei, B.; Stumphauser, N.; Molontay, R. Traits versus Grades-The Incremental Predictive Power of Positive Psychological Factors over Pre-Enrollment Achievement Measures on Academic Performance. Appl. Sci. 2021, 11, 1744. https://doi.org/10.3390/ app11041744

\section{Academic Editor:}

Antonio Fernández-Caballero

Received: 17 December 2020

Accepted: 11 February 2021

Published: 16 February 2021

Publisher's Note: MDPI stays neutral with regard to jurisdictional claims in published maps and institutional affiliations.

Copyright: (c) 2021 by the authors. Licensee MDPI, Basel, Switzerland. This article is an open access article distributed under the terms and conditions of the Creative Commons Attribution (CC BY) license (https:// creativecommons.org/licenses/by/ $4.0 /)$.

\begin{abstract}
Understanding what (and to what extent) psychological factors affect university performance has attracted a lot of research interest recently. In this paper, we use logistic regression models to study the incremental predictive power of positive psychological factors over pre-enrollment achievement measures on academic performance. The study is based on the data of 302 business and economics undergraduate students from the Budapest University of Technology and Economics. Coping proved to be the most important factor that sheds light on the importance of stress management for students. We also found that using properly chosen psychological factors measuring coping, personality traits, psychological immune system, emotional intelligence, and PERMA ( $\mathrm{P}$-positive emotion, E-engagement, $\mathrm{R}$-relationships, $\mathrm{M}$-meaning, A-accomplishments) factors, together with the university entrance score and academic performance can be predicted significantly better than solely relying on pre-enrollment achievement measures.
\end{abstract}

Keywords: university performance; incremental predictive power; predictive analysis; pre-enrollment achievement measures; personality traits; psychological factors; PERMA; emotional intelligence; coping; stress management

\section{Introduction}

High dropout rates and delayed completion in higher education is a moral and economic problem as well. It represents a cost for the government and society, an unnecessary expense for the family, and an experience of failure for the university student. To identify students at risk of academic failure at the time of enrollment, we studied the underlying variables of academic success by investigating both pre-enrollment achievement measures and the psychological profiles of the students. Identifying at-risk students as early as possible enables decision-makers to initiate targeted development programs to prevent dropout.

The majority of the literature investigating university performance and dropout prediction relies on prior achievement indicators and personal details [1,2]. It was demonstrated in several studies that university performance can be predicted efficiently based on preenrollment achievement measures using sophisticated machine learning algorithms [3-5]. For example, Nagy and Molontay achieved 73\% accuracy in identifying future dropouts of the Budapest University of Technology and Economics [6].

On the other hand, the question comes up as to whether better prediction performance could be achieved if psychological factors were also taken into account. While pre-enrollment achievement measures are usually directly available for higher education institutes, universities normally do not have data on their students' psychological factors. In this paper, we investigate a wide range of psychological factors and study their incremental predictive powers over pre-enrollment achievement measures on university 
performance. These factors are measured using lengthy questionnaires that makes it cumbersome to collect all of these measures from all incoming students. On the other hand, by identifying a small set of psychological factors that have significant incremental predictive power, we suggest a more feasible strategy with direct applications: measuring only these important factors at the time of enrollment and using the psychological data together with the pre-enrollment achievement measures to identify students at risk of academic failure more efficiently.

Researchers have been exploring the connection between students' academic success and personality traits, motivations, or drives. The challenge is to find the right set of variables that affect the performance the most. Based on the meta-analysis by Schneider and Preckel, intelligence and pre-achievement of students are more related to university success than personality and motivational factors [7]. However, non-cognitive characteristics are also found to have a strong predictive power on students' academic success since these characteristics play an important role in students' motivation, achievements, and interests [7-11].

The strong effect of personality attributes on university performance has been shown in many studies $[12,13]$. For example, conscientiousness is found to play a key role in almost every academic field, from programming [14] through psychology [15], to business and management [16]. In addition to conscientiousness, agreeableness and openness also play an important role in academic achievement, according to a meta-analysis by Poropat [12]. However, there are also some domain-specific differences, for instance, regarding openness to experience with management students-conscientiousness and extraversion seem to be the most important factors $[17,18]$, while with other students, other traits are found to be more important $[10,11]$. Eysenck's [19] super traits also have high predictive validity on academic performance [20]. Emotional stability and neuroticism are shown to be related to grades and performance [21]. Moreover, Eysenck's traits not only fit the lexical criteria, but super trait extraversion (and introversion, which refers to the degree of sociability); neuroticism (from emotional instability to emotional stability) and psychoticism also have strong biological backgrounds [22,23].

The above-mentioned set of personality factors and motivations seem to be more important than being simply smart at the university-level [24]. Achievement motivation, namely the tendency to reach success and avoid failures, can clarify this picture, because motivation gives focus and energy to fulfil personality-based aims [25]; thus, it has a significant impact on learning efforts [26]. Therefore, internal or intrinsic motivation is a relevant predictor of success and is associated with personality [24].

We propose that not only well-studied intelligence, personality, and motivational factors are associated with academic achievement, but the below-listed set of positive psychological competencies may also have an important role in predicting academic success. As a new approach in psychology, positive psychology focuses on a well-lived life and places special emphasis on the positive role of emotions in our lives. For the selection of these additional psychological variables, we used three criteria: they describe emotionrelated competencies in a positive way, they can be easily developed even in a university context, and there is research evidence that the phenomenon is linked with academic success as detailed below.

According to Bar-On [27] (p. 57) "emotional-social intelligence is an array of interrelated emotional and social competencies and skills that determine how effectively individuals understand and express themselves, understand others and relate with them, and cope with daily demands, challenges and pressures". Current research findings strengthen the notion that emotional intelligence (EI) or emotional intelligence quotient (EQ) is not only related to workplace and social competency, but also to academic success; however, the size of the effect is culture- and field-dependent [28-33]. Awareness of emotions has a strong effect on academic performance that can be explained by the fact that dealing with educational challenges requires emotional awareness, flexibility, self-motivation, self-control, the ability to handle the emotions of others, and influence the motivations of others [28,34]. 
The transition to higher education is usually a stressful situation that requires emotional competencies. Parker et al. [32] found that some EI factors, such as intrapersonal, stress management, and adaptability, play an important role in academic success, and can explain $8-10 \%$ of the variability on grade point average (GPA). How stress management, personality, and EI are related is a scientific debate; however, there is some empirical evidence that suggests that these phenomena influence academic success. Saklofske et al. [35] found that EI may play a mediating role in the relationship between personality factors and academic success, because we must take stress into consideration. EI plays an important role in handling stress and, hereby, reaching academic success. Based on this approach, coping skills and strategies can also have strong predictive power on university performance. MacCann et al. [36] focused on coping styles that influence performance. Problem-focused coping is a stable basis of performance, while emotion-focused coping strategies have different effects in this special context. Their study pans out the subjective well-being of students, and the potential associations with coping and success.

One important facet of the detailed construct of well-being is grit. Grit is the ability to persevere with passion for long-term goals, despite setbacks [37]. Grit is closely related to personality, especially to conscientiousness, but can also add something new in predicting academic success, because narrower, more specific facets, can have better predictive power [38]. We note that self-control is closely related to grit, but they are different, because self-control (as part of EI) refers to the ability to work hard for short-term goals, and it is related to the presence of temptation, while grit is primarily for the long-term, and it is mostly for intrinsically motivated goals [39].

These positive psychological concepts are strongly linked. Emotional intelligence and grit could be related to other source competencies, such as coping and the psychological immune system. The psychological immune system collects traits and skills that are helpful to deal with stress [40]. This is an integrative structure for adaptation and coping, which contains cognitive, motivational, and behavioral dimensions. With a well-functioning psychological immune system, the stress-resistance period is longer, emotional stability is higher, and it promotes healthy coping and growing under hard circumstances. These components are consonant and refer to the PERMA ( $\mathrm{P}$ - positive emotion, E-engagement, $\mathrm{R}$-relationships, $\mathrm{M}$-meaning, $\mathrm{A}$-accomplishments) model in terms of positive psychology [41,42]. The pillars of well-being are positive emotions, engagement, relationships, meaning, and accomplishments, which are also associated with success $[43,44]$. Some research evidence exists already proving that PERMA components are associated with academic success $[45,46]$; moreover, PERMA factors support disabled students as a buffer to reach academic success [47].

While exploring the characteristics of students, we placed special focus on personality traits [48] and the aforementioned positive source competencies [22,24,28,32,35,36,38,43-48], as they can change and improve, and, thus, provide an important intervention point in increasing the success of students and prevent at-risk students from dropping out. We propose that certain personality variables, positive psychological resource competencies, and demographic variables of university students determine their success at university, and can increase the predictive power of pre-enrollment achievement measures. The present study was guided by the following main research questions:

- What incremental predictive power do certain psychological factors (e.g., personality traits and positive source competencies as emotional intelligence, coping skills, psychological immunity, grit, and PERMA) have over pre-enrollment achievement measures on academic success?

- What set of psychological factors should be measured at the time of enrollment that make identifying students at risk of academic failure more efficient?

\section{Materials and Methods}

In this section, we present our data together with the used methodology. We gathered data to get a detailed picture of economics and management students: their personality 
variables and positive psychological factors (resources, psychological immunity, subjective well-being, and emotional and social skills), and their coping skills. Moreover, we collected data about their pre-enrollment achievement measures and university performance (GPA). We built an integrative model to examine what incremental predictive validity psychological attributes have over pre-enrollment achievement measures on academic performance

\subsection{Participants}

This study is based on the data collected among first-year students of management and economics at the Budapest University of Technology and Economics enrolled in 2018 and 2019. Participants were recruited from a large psychology class and were asked if they would volunteer to participate in this study by filling out a set of surveys at the beginning of their first semester. Almost all of the students filled out the questionnaire $(n=436)$ and $69.3 \%$ of the participants $(n=302)$ gave permission to connect their answers with data stored in the educational administrative system to retrieve their first-year grade point averages (FGPAs) and gain access to their university entrance scores (UESs), which revealed their prior academic achievements.

To combine the psychological factors with academic success, we also monitored the performance of the respondents in the first academic year of their undergraduate programs. On average, students took 62 university credits over the two semesters and received a first-year GPA of 3.4 (out of 5).

The data set included data from 180 women and 122 men; the average age at the time of completing the questionnaire was 19.5 years. Moreover, $52.6 \%$ of the students lived with their parents, while $22.5 \%$ of the respondents lived in rented apartments. The vast majority of the respondents $(88.1 \%)$ came to the university directly from high school.

All of the data were collected and stored cautiously, and personal data were anonymized.

\subsection{Measures}

In this section, we describe our measurement tools. Table 1 summarizes the descriptive statistics and psychometric attributes of the used tools. Apart from the first-year GPA and the university entrance score, all of the measures were collected by a set of surveys.

Table 1. Descriptive statistics and psychometric attributes of the set of measured variables.

\begin{tabular}{|c|c|c|c|c|c|c|c|c|}
\hline Factor Group & Factor & Min & $\operatorname{Max}$ & Mean & Std & Skewness & Kurtosis & $\begin{array}{c}\text { Cronbach's } \\
\text { Alpha }\end{array}$ \\
\hline \multirow{4}{*}{$\begin{array}{c}\text { Eysenck } \\
\text { Personality } \\
\text { Inventory }\end{array}$} & extraversion and introversion & 0.0 & 32.0 & 19.2 & 8.1 & -0.3 & -0.8 & \multirow{4}{*}{0.581} \\
\hline & emotional stability & 4.0 & 38.0 & 24.2 & 8.1 & -0.2 & -0.8 & \\
\hline & rigidity & 2.0 & 30.0 & 19.0 & 5.4 & -0.4 & -0.1 & \\
\hline & honesty & 0.0 & 14.0 & 5.1 & 2.9 & 0.4 & -0.3 & \\
\hline Grit & Grit point & 1.9 & 4.8 & 3.3 & 0.5 & 0.0 & -0.2 & 0.734 \\
\hline \multirow{8}{*}{ Coping } & problem focus & 25.0 & 100.0 & 72.3 & 12.4 & -0.4 & 0.7 & \multirow{8}{*}{0.907} \\
\hline & support-seeking & 25.0 & 100.0 & 71.1 & 17.4 & -0.6 & 0.0 & \\
\hline & impulse control & 25.0 & 100.0 & 66.7 & 9.2 & -0.7 & 3.2 & \\
\hline & attention diversion & 25.0 & 100.0 & 64.7 & 10.8 & -0.4 & 1.2 & \\
\hline & emotion focus & 25.0 & 100.0 & 61.8 & 11.1 & -0.2 & 0.8 & \\
\hline & acting out & 25.0 & 125.0 & 74.6 & 22.0 & 0.0 & -0.9 & \\
\hline & self-punishment & 25.0 & 100.0 & 63.1 & 16.8 & 0.1 & -0.4 & \\
\hline & acquiescence & 25.0 & 100.0 & 59.9 & 15.4 & 0.1 & -0.1 & \\
\hline
\end{tabular}


Table 1. Cont.

\begin{tabular}{|c|c|c|c|c|c|c|c|c|}
\hline Factor Group & Factor & Min & Max & Mean & Std & Skewness & Kurtosis & $\begin{array}{c}\text { Cronbach's } \\
\text { Alpha }\end{array}$ \\
\hline \multirow{7}{*}{$\begin{array}{l}\text { Psychological } \\
\text { Immune } \\
\text { System (PI) } \\
\text { monitoring }\end{array}$} & positive thinking & 5.0 & 20.0 & 15.0 & 3.3 & -0.6 & 0.1 & \multirow{7}{*}{0.904} \\
\hline & sense of control & 6.0 & 20.0 & 14.1 & 2.4 & -0.3 & 0.0 & \\
\hline & feeling of growth & 5.0 & 20.0 & 15.0 & 3.5 & -0.6 & -0.1 & \\
\hline & challenge seeking & 5.0 & 20.0 & 14.3 & 3.3 & -0.3 & -0.2 & \\
\hline & goal orientation & 7.0 & 20.0 & 14.6 & 2.9 & -0.1 & -0.4 & \\
\hline & coherence & 7.0 & 20.0 & 15.0 & 3.2 & -0.1 & -0.8 & \\
\hline & social source monitoring & 5.0 & 20.0 & 15.1 & 3.2 & -0.3 & -0.5 & \\
\hline \multirow{5}{*}{ PI mobilizing } & self-efficiency & 8.0 & 20.0 & 14.8 & 2.9 & -0.1 & -0.6 & \multirow{5}{*}{0.907} \\
\hline & creativity & 6.0 & 20.0 & 14.5 & 3.2 & -0.3 & -0.4 & \\
\hline & social source founding skills & 5.0 & 20.0 & 13.7 & 3.1 & -0.2 & -0.1 & \\
\hline & mobilizing skills & 5.0 & 20.0 & 15.0 & 3.2 & -0.3 & -0.5 & \\
\hline & learned optimism & 6.0 & 20.0 & 15.1 & 3.4 & -0.4 & -0.6 & \\
\hline \multirow{4}{*}{ PI self-control } & impulse control & 5.0 & 20.0 & 13.3 & 2.9 & 0.0 & -0.1 & \multirow{4}{*}{0.882} \\
\hline & irritability-control & 5.0 & 20.0 & 12.2 & 3.5 & 0.2 & -0.5 & \\
\hline & emotion control & 5.0 & 19.0 & 11.9 & 3.5 & 0.0 & -0.8 & \\
\hline & mindfulness-synchronization skill & 5.0 & 20.0 & 12.2 & 3.4 & -0.1 & -0.7 & \\
\hline \multirow{5}{*}{$\begin{array}{l}\text { Emotional } \\
\text { intelligence } \\
\text { Quotient (EQ) } \\
\text { intrapersonal }\end{array}$} & assertiveness & 33.3 & 96.7 & 67.5 & 12.8 & -0.2 & -0.3 & \multirow{5}{*}{0.939} \\
\hline & self-awareness & 19.0 & 100.0 & 67.2 & 17.0 & -0.3 & -0.3 & \\
\hline & self-regard & 18.5 & 100.0 & 65.5 & 19.3 & -0.3 & -0.6 & \\
\hline & independence & 18.8 & 87.5 & 56.7 & 12.8 & -0.4 & -0.1 & \\
\hline & self-actualization & 38.1 & 100.0 & 78.3 & 14.9 & -0.4 & -0.7 & \\
\hline \multirow{3}{*}{$\begin{array}{c}\mathrm{EQ} \\
\text { interpersonal }\end{array}$} & empathy & 33.3 & 100.0 & 73.9 & 14.3 & -0.5 & -0.1 & \multirow{3}{*}{0.906} \\
\hline & social responsibility & 37.0 & 100.0 & 76.7 & 12.2 & -0.5 & -0.2 & \\
\hline & interpersonal relationship & 36.7 & 100.0 & 75.0 & 13.1 & -0.3 & -0.5 & \\
\hline \multirow{3}{*}{ EQ adaptation } & reality testing & 20.0 & 90.0 & 63.2 & 11.4 & -0.3 & 0.2 & \multirow{3}{*}{0.858} \\
\hline & flexibility & 22.9 & 92.5 & 62.8 & 13.4 & -0.3 & -0.3 & \\
\hline & problem-solving & 37.5 & 100.0 & 73.2 & 13.0 & -0.3 & 0.0 & \\
\hline \multirow{2}{*}{$\begin{array}{l}\text { EQ stressman- } \\
\text { agement }\end{array}$} & stress tolerance & 29.6 & 91.1 & 63.0 & 9.0 & -0.2 & 0.2 & \multirow{2}{*}{0.817} \\
\hline & impulse control & 24.1 & 100.0 & 64.1 & 16.9 & -0.1 & -0.5 & \\
\hline \multirow{2}{*}{$\begin{array}{l}\text { EQ moodand } \\
\text { motivation }\end{array}$} & optimism & 27.1 & 100.0 & 72.1 & 15.0 & -0.5 & 0.1 & \multirow{2}{*}{0.915} \\
\hline & happiness & 48.1 & 100.0 & 79.2 & 13.8 & -0.5 & -0.7 & \\
\hline \multirow{9}{*}{ PERMA } & positivity $(\mathrm{P})$ & 3.0 & 30.0 & 21.3 & 4.9 & -0.7 & 0.4 & 0.824 \\
\hline & engagement (E) & 11.0 & 30.0 & 22.1 & 3.7 & -0.5 & 0.1 & 0.385 \\
\hline & relationship (R) & 5.0 & 30.0 & 23.2 & 4.9 & -0.8 & 0.3 & 0.809 \\
\hline & meaning $(\mathrm{M})$ & 6.0 & 30.0 & 22.8 & 4.3 & -0.8 & 0.9 & 0.803 \\
\hline & accomplishment (A) & 8.0 & 30.0 & 22.6 & 4.0 & -0.9 & 1.1 & 0.718 \\
\hline & health & 4.0 & 30.0 & 21.1 & 5.6 & -0.6 & 0.0 & 0.881 \\
\hline & negativity & 7.0 & 25.0 & 17.0 & 3.5 & 0.1 & -0.6 & 0.766 \\
\hline & happiness & 1.0 & 10.0 & 7.5 & 1.7 & -0.7 & 0.4 & - \\
\hline & loneliness & 1.0 & 10.0 & 4.9 & 2.5 & 0.2 & -1.1 & - \\
\hline High school & university entrance score & 331.0 & 491.0 & 402.8 & 34.1 & -0.2 & -0.8 & - \\
\hline
\end{tabular}


First, to collect some sociodemographic variables, we asked the students about their age, gender, family, and other living circumstances. The second survey was the Eysenck Personality Questionnaire (EPI) [49-51]. This test measures the personality in three main dimensions: extraversion-introversion (E: the tendency to seek peers, activity, and relationships and I is the opposite), neuroticism-emotional stability (N: the tendency of how much people are influenced by environmental emotional cues), and psychoticism (P: this scale is associated with aggression, more masculine behavior, and non-conformity). To measure the conformity and lying tendency, there is a fourth subscale integrated into the inventory (L). The Hungarian version of the questionnaire contains 58 questions and the students' task was to decide whether the item applied to them or not. The psychometric properties of the test are acceptable based on a meta-analysis; Cronbach's $\alpha$ (alpha) values (a measure of internal consistency) are between 0.58 and 0.85 [52].

The third survey was the Emotional Intelligence Inventory, developed by Bar-On $[53,54]$. The test contains 121 items and asks students for a self-report on how much the items describe them, using a 5-point Likert-scale. Emotional intelligence is divided into 5 scales with a different number of subscales: intrapersonal scale, which assesses the self-awareness and self-expression (subscales are self-regard, emotional self-awareness, assertiveness, independence, and self-actualization); interpersonal scale, which measures social awareness and interpersonal relationship (subscales are empathy, social responsibility, and interpersonal relationship); stress management scale, which assesses emotional management and regulation (subscales are stress tolerance and impulse control); adaptability scale, which measures change management (subscales are reality-testing, flexibility, and problem-solving), and general mood scale, which measures competencies of self-motivation (subscales are optimism and happiness) [55,56] (p. 21). This is a widely used emotional intelligence test with acceptable psychometric properties: high Cronbach $\alpha$-s on each scale and subscale (0.67-0.79) and good test-retest reliability, even in a multicultural context [53,55].

Next, we measured the positive source competencies with the help of PERMA Profiler, this is the first holistic measurement tool of well-being [42]. We used the 23-item questionnaire; the refined model has acceptable psychometric attributes with $\alpha$-s between 0.60 and 0.94 on each scale, except 2 scales (happiness and loneliness), which contain only 1 item [42]. For PERMA happiness and loneliness, there are no $\alpha$-s because these factors contain only one question, so the calculation of the value is unnecessary. The final structure has seven subscales, five from the original PERMA structure: positive emotion, engagement, positive relationship, meaning or purpose in life, accomplishment, and two new factors of the refined model: negative emotion, physical health. The authors suggest using these factors separately and not as a general PERMA score because it seems to be an umbrella term [42].

We also used the Grit-Short (Grit-S) questionnaire, which is dedicated to measuring perseverance (at a trait-level) and the passion for long-term goals. It contains 8 items, and students indicate how much the items describe them using a Likert-scale. This short questionnaire has strong psychometric characteristics ( $\alpha-s=0.82$ and 0.84$)$ [57].

As behavioral factors, we measured stress management and coping skills using two questionnaires with acceptable psychometric characteristics developed by Oláh [58,59]. The first tool was the coping preferences test that contains 80 items with a 4-point Likert-scale in which students decide how often they use the offered answer in a stressful situation. The test gives a profile of preferences on 8 coping mechanisms: problem-focused strategies (e.g., problem-focused reaction), support-finding strategies (e.g., support seeking), and emotion-focused strategies (e.g., impulse control, emotion-focused actions, acting out, self-punishment, acquiescence, and attention diversion). As another aspect of coping, the measurement of the psychological immune system focused on mental and psychological aspect of stress management. The test contains 80 items with a 4-points Likert-scale. After the assessment, we get 16 factors in three subsystems of the well-functioning psychological immune system: monitoring-approximate system (positive thinking, sense of control, sense of coherence, feeling of growth, challenge seeking, social source monitoring, and goal orientation), mobilizing-generating subsystem (self-efficiency, creativity, mobilizing 
skills, social source founding skills, learned optimism), and self-regulating sub-system (mindfulness--synchronization skill, impulse control, irritability-control, and control of emotions) [60,61].

To measure prior academic achievement, we used the university entrance score (UES). The nationally standardized Hungarian university entrance score is a composite score of pre-enrollment achievement measures and was shown to have high predictive validity [62] Students applying for undergraduate programs in Hungary gain a nationally determined UES, which mostly relies on the score of Matura exit examination and high school grades and has a maximum value of 500. The exact calculation of the UES is detailed in the paper by Nagy and Molontay [62].

Using the aforementioned psychological and pre-enrollment achievement measures, we aimed to predict university performance and identify at-risk students. Although university success and academic achievement can be defined in many ways, we used a traditional measure of academic success: first-year GPA (FGPA) retrieved from the official register.

\subsection{Methods}

We used tenfold cross-validated logistic regression models to measure the predictive and incremental predictive validity of the factors [63]. Logistic regression makes it possible to investigate the combined incremental power of psychological factors and obtain an efficient predictive model to identify students at risk of dropout.

The target (outcome) variable was chosen to be the FGPA as a good proxy of academic success. We aim to predict the FGPA based on the psychological factors collected at the beginning of the first semester and pre-enrollment achievement measures. The continuous target variable ( 1 to 5 ) was converted to a binary variable by trimming at 3.0 to obtain binary labels. A student with an FGPA below 3.0 is considered a student at risk of academic failure, while a student with an FGPA above 3.0 is considered a fairly performing student. While the threshold of 3.0 FGPA might seem arbitrary, our choice is also supported by the fact that this is the cut-off value where a student loses his/her state-funded scholarship and is re-classified to a fee-paying status. Using the threshold of a FGPA of 3.0, we had 80 at-risk students and 222 fairly performing students.

The logistic regression models were run with tenfold cross-validation, i.e., in each case, data were divided into 10 parts ( 9 parts for training and 1 for testing in each possible combination). Area under the curve (AUC) scores were used to evaluate the predictive performance of the models. AUC stands for the area under the receiver operating characteristic (ROC) curve that is the plot of the true positive rate against the false positive rate at various threshold settings. AUC value is a widespread performance indicator, especially for imbalanced class distribution. The higher the AUC score, the better the predictive power the model has $[63,64]$. In a probabilistic interpretation, the AUC shows the probability that our logistic regression model outputs a higher dropout probability for a randomly chosen at-risk student than for a randomly chosen fairly performing one.

To compare the incremental predictive power of various psychological factors over pre-enrollment achievement measures, we investigated whether the increase in the AUC score was significant. More precisely, we tested the null hypothesis that the two AUC scores were equal $[1,2]$. The test statistic relied on the correlation coefficient of the two AUC scores and on the independent standard errors. The exact calculation of the test statistic is presented in [62,65].

\section{Results}

In this section, we present the incremental predictive powers the psychological factors have over pre-enrollment achievement measures. University entrance score, as a composite score of various pre-enrollment achievement measures, has a strong predictive power on university success measured by the binary outcome variable, derived from the cumulative FGPA. Solely relying on the UES, the binary outcome can be predicted with an AUC of 0.737 
using a logistic regression model with tenfold cross-validation. In the following, we study how the predictive power increases if we supplement the UES with psychological factors. Moreover, we also investigate what factors and what groups of factors have significant incremental predictive power.

\subsection{Positive Psychological Factors}

We observed that, among positive psychological factors, the coping factor and the psychological immunity (PI) self-control subsystem had the strongest incremental predictive power over pre-enrollment achievement measures on university performance. The results are shown in Table 2 . The coping factor had the only significant improvement at the 0.1 level $(p=0.0986)$. It increased the AUC from 0.737 to 0.778 .

Table 2. The predictive power (area under the curve (AUC) values) of psychological factors combined with the university entrance score. The AUC of the university entrance score (UES) alone was 0.737 ; the other AUC values should be interpreted in comparison with this value.). ${ }^{*}: p<0.1$.

\begin{tabular}{ccc}
\hline Groups & Factors & AUC (with UES) \\
\hline \multirow{3}{*}{ Coping skills and } & coping & $\mathbf{0 . 7 7 8}$ \\
psychological immunity & PI self-control part & $\mathbf{0 . 7 4 5}$ \\
& PI monitoring part & 0.704 \\
& PI mobilizing part & 0.728 \\
\hline \multirow{2}{*}{ Emotional intelligence } & EQ intrapersonal part & 0.735 \\
& EQ interpersonal part & 0.728 \\
& EQ stress-management & 0.722 \\
& EQ adaptation part & 0.722 \\
& EQ mood and motivation & 0.715 \\
\hline & Grit & $\mathbf{0 . 7 4 0}$ \\
& PERMAnegativity & $\mathbf{0 . 7 3 8}$ \\
& PERMA health & $\mathbf{0 . 7 3 7}$ \\
& PERMA accomplishment & 0.734 \\
& PERMA happiness & 0.733 \\
& PERMA meaning & 0.732 \\
& PERMA positivity & 0.731 \\
& PERMA loneliness & 0.731 \\
& PERMA engagement & 0.729 \\
& PERMA relationship & 0.729 \\
\hline Stable psychological factors & EPI & $\mathbf{0 . 7 6 4}$ \\
\hline
\end{tabular}

The emotional intelligence factor can also be interpreted in its subsystems due to the multifaceted personality traits covered; the results can also be found in Table 2. Regarding the independent incremental predictive power of the parts of the EQ, it can be concluded that they did not have significant incremental predictive power.

Positive source competencies included the factors of grit and PERMA. PERMA factors are worth considering separately, according to their attributes, such as EQ and PI. Grit, PERMA negativity, and health factors had some incremental predictive power, but the increase was much weaker than in the case of the coping factor (see Table 2).

\subsection{Stable Personality Factors}

Outcomes of EPI were stable factors of personality. It is apparent that EPI factor had some incremental predictive power over the university entrance score since the AUC increased to 0.764 (see Table 2), but it cannot be considered as significant at the 0.1 level $(p=0.1452)$.

Overall, 6 of the 20 examined factors (30\%) showed incremental predictive power over pre-enrollment achievement measures (marked by bold in Table 2), and only the coping factor had a significant improvement over the UES. 
After measuring the incremental predictive power of the individual factors, we investigated the incremental predictive power of the combinations of the factors. The improvement in AUC values was examined considering groups of two, three, four, five, and six factors, in addition to the pre-enrollment achievement measures.

\subsection{Incremental Predictive Power of Factor Groups}

Providing that the higher education institution has the resources to measure more than one psychological factor, the question arises as to what factors should be collected jointly to increase the predictive power the most. We answer this by investigating factor groups (of up to six factors).

\subsubsection{Incremental Predictive Power of Factor Groups: Pairs}

We investigated what pairs of psychological factors had incremental predictive power over individual factors and the UES. Thus, we selected those pairs of psychological factors that had higher incremental predictive power over pre-enrollment achievement measures than any of the factors of the given pair had. We also investigated whether the improvement in the AUC score was significant in comparison with the best result achieved in the previous section, namely the predictive power of the UES and the coping factor. We observed incremental power in the case of 18 pairs out of the 190 possible pairs (9.5\%). The combination of coping and EPI gave the most outstanding result, with 0.806 AUC value; this improvement in the AUC score was significant at the 0.1 level $(p=0.0545)$ compared to the improvement achieved by only using the coping factor. The pair of coping and EPI was the only pair that had significant improvement to the predictive power of the combination of coping and UES. On the other hand, there were six other pairs with significant improvements compared to the UES solely, these were the pairs that coping factor was a member of (see Figure 1). In Table 3 the "Number of pairs" column shows the number of pairs with (significant) incremental predictive power that the given factor contributed to. In this regard, coping, EPI, PI self-control, and PERMA accomplishment stood out, accounting for at least $22 \%$ of all pairs of factors with incremental predictive power. Figure 1 shows a heatmap of the AUC values of the pairs. It suggests that coping not only had a very strong incremental predictive power over pre-enrollment achievement measures but also over the majority of other psychological factors.

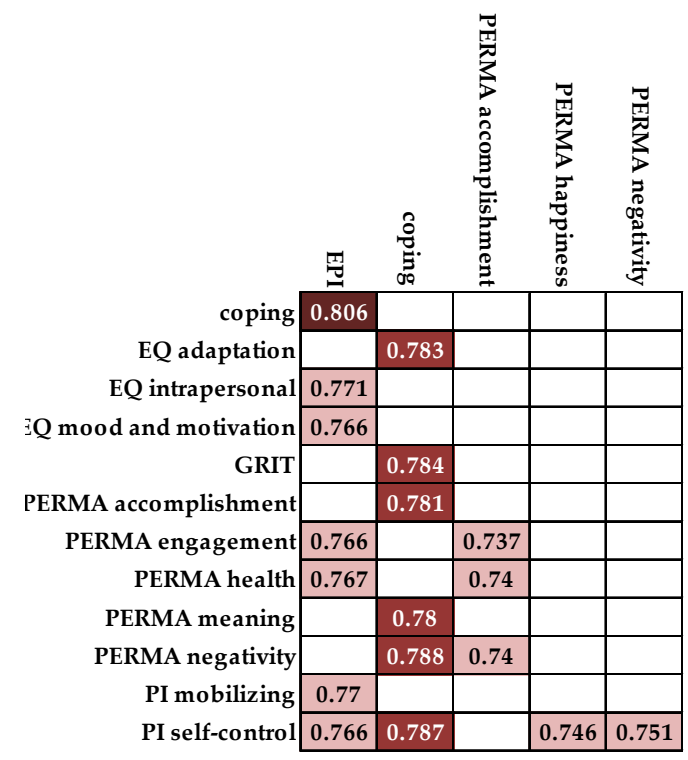

Figure 1. The AUC values of pairs with incremental predictive power (higher AUC values than any of the factors of the given pair has). The dark purple background indicates significant increase to the improvement achievement by the coping factor. Medium purple background indicates significant increase to the prediction power of the UES (university entrance score is always incorporated in the models.). 
Table 3. The number of groups (pairs, triplets, quadruplets, quintuplets, sextuplets) and the ratio of all groups with additional incremental predictive power where the given factor contributes to. The second number in each column reflects to the number and ratio of groups out of the groups with incremental predictive power that have significant prediction gain (at the 0.1 level) compared to the prediction power of the UES. * The ratio in all column shows what percentage of all factor groups with (significant) incremental power the given factor was included in. This is a good metric for finding what factors increase the predictive power typically.

\begin{tabular}{|c|c|c|c|c|c|c|}
\hline Factor & $\begin{array}{c}\text { Number of } \\
\text { Pairs }\end{array}$ & $\begin{array}{c}\text { Number of } \\
\text { Triplets }\end{array}$ & $\begin{array}{l}\text { Number of } \\
\text { Quadruplets }\end{array}$ & $\begin{array}{l}\text { Number of } \\
\text { Quintuplets }\end{array}$ & $\begin{array}{l}\text { Number of } \\
\text { Sextuplets }\end{array}$ & Ratio in All * \\
\hline PERMA negativity & $3 / 1$ & $11 / 4$ & $12 / 7$ & $21 / 13$ & 0 & $54.5 \% / 61.0 \%$ \\
\hline coping & $7 / 7$ & $11 / 11$ & $7 / 7$ & $12 / 12$ & 0 & $43.2 \% / 92.7 \%$ \\
\hline PI self-control & $4 / 1$ & $6 / 2$ & $7 / 3$ & $20 / 11$ & 0 & $43.2 \% / 41.5 \%$ \\
\hline EPI & $7 / 1$ & $8 / 3$ & $6 / 3$ & $10 / 4$ & 0 & $36.4 \% / 26.8 \%$ \\
\hline PERMA health & $2 / 0$ & $3 / 2$ & $7 / 2$ & $10 / 7$ & 0 & $26.1 \% / 26.8 \%$ \\
\hline EQ intrapersonal & $1 / 0$ & $4 / 0$ & $7 / 1$ & $8 / 2$ & 0 & $22.7 \% / 7.3 \%$ \\
\hline PERMA accomplishment & $4 / 1$ & $3 / 2$ & $5 / 1$ & $7 / 1$ & 0 & $21.6 \% / 12.2 \%$ \\
\hline PERMA engagement & $2 / 0$ & $2 / 0$ & $3 / 0$ & $6 / 0$ & 0 & $14.8 \% / 0.0 \%$ \\
\hline EQ adaptation & $1 / 1$ & $4 / 4$ & $2 / 2$ & $4 / 4$ & 0 & $12.5 \% / 26.8 \%$ \\
\hline PERMA happiness & $1 / 0$ & $0 / 0$ & $1 / 1$ & $7 / 4$ & 0 & $10.2 \% / 12.2 \%$ \\
\hline PERMA loneliness & $0 / 0$ & $2 / 0$ & $1 / 0$ & $6 / 4$ & 0 & $10.2 \% / 9.8 \%$ \\
\hline PERMA meaning & $1 / 1$ & $1 / 1$ & $3 / 1$ & $4 / 2$ & 0 & $10.2 \% / 12.2 \%$ \\
\hline Grit & $1 / 1$ & $4 / 3$ & $2 / 2$ & $1 / 1$ & 0 & $10.2 \% / 17.1 \%$ \\
\hline PERMA positivity & $0 / 0$ & $1 / 1$ & $3 / 1$ & $3 / 2$ & 0 & $8.0 \% / 9.8 \%$ \\
\hline EQ interpersonal & $0 / 0$ & $0 / 0$ & $2 / 1$ & $3 / 2$ & 0 & $5.7 \% / 7.3 \%$ \\
\hline PERMA relationship & $0 / 0$ & $0 / 0$ & $2 / 0$ & $2 / 1$ & 0 & $4.5 \% / 2.4 \%$ \\
\hline EQ mood and motivation & $1 / 0$ & $2 / 0$ & $1 / 0$ & $0 / 0$ & 0 & $4.5 \% / 0.0 \%$ \\
\hline EQ stress-management & $0 / 0$ & $1 / 0$ & $1 / 0$ & $1 / 0$ & 0 & $3.4 \% / 0.0 \%$ \\
\hline PI mobilizing & $1 / 0$ & $0 / 0$ & $0 / 0$ & $0 / 0$ & 0 & $1.1 \% / 0.0 \%$ \\
\hline PI monitor & $0 / 0$ & $0 / 0$ & $0 / 0$ & $0 / 0$ & 0 & $0.0 \% / 0.0 \%$ \\
\hline
\end{tabular}

\subsubsection{Incremental Predictive Power of Factor Groups: Triplets}

Next, we investigated whether using three psychological factors could increase the predictive power in comparison with the predictive power of their subsets. Out of the 1140 triplets, an improvement was measured in only 21 cases $(1.8 \%)$. On the other hand, we observed no significant improvement to the best performing pair from the previous section, namely the combination of the UES, coping, and EPI at the 0.1 level, while 11 triplets showed significant improvement to the UES solely. The best performing one was the triplet of coping, EPI, and PERMA health, which gained an AUC of 0.810. In Table 3 the "Number of triplets" column indicates the number of triplets with (significant) incremental predictive power that the given factor contributes to. In this case, the coping and PERMA negativity factors were prominently included in triplets with incremental predictive power, in more than $52 \%$ of all. In addition, EPI and PI self-control were also present in many triplets, namely 8 and 6 (38\% and 29\%, respectively, of all 21 groups). Some of the PERMA factors (positivity, meaning, happiness, relationship), EQ factors (stress-management, interpersonal part), and PI subsystems (monitoring and mobilizing) were included in a few groups (less than 3\%). Table 4 shows the predictive power of the five best triplets according to the AUC scores.

Table 4. The predictive power of the five best triplets.

\begin{tabular}{cc}
\hline Groups & AUC (with UES) \\
\hline coping, EPI, PERMA health & 0.810 \\
coping, EPI, PERMA negativity & 0.809 \\
coping, EPI, PERMA positivity & 0.806 \\
coping, PERMA meaning, PERMA negativity & 0.790 \\
coping, grit, PI self-control & 0.789 \\
\hline
\end{tabular}




\subsubsection{Incremental Power of Factor Groups: Quadruplets}

We studied whether it was worth measuring four psychological factors, i.e., whether it had any incremental predictive power over using only triplets. There was an improvement in predictive power in a total of 18 quadruplets out of the 4845 candidate groups $(0.4 \%)$. On the other hand, no significant improvement was observed at the 0.1 level in comparison with the combination of the UES, coping, and EPI, while eight quadruplets showed further significant improvement to the UES. The most outstanding improvement was achieved by coping, EPI, PERMA positivity, and PERMA negativity with a $p$ value of $0.0075 \mathrm{com}$ pared to the AUC of the UES. Using these sets of factors together with pre-enrollment achievement measures resulted in a 7 percentage point gain in AUC results, compared to the predictive power of UES. In Table 3 the "Number of quadruplets" column indicates the number of quadruplets with (significant) incremental predictive power that the given factor contributes to. In this case, the PERMA negativity factor is present in $67 \%$ of all quadruplets with incremental predictive power. Moreover, coping, PI, self-control, EQ intrapersonal part, and PERMA health factors are important in 39\% of the quadruplets. From the best eight factor groups (more than 0.781 AUC scores), seven had coping and seven had PERMA negativity in them.

\subsubsection{Incremental Power of Factor Groups: Quintuplets and Sextuplets}

We observed an improvement in predictive power in only 25 groups out of 15,504 possible quintuplets $(0.16 \%)$. From this, 14 showed significant improvement to the UES (with an increase in AUC by 4.3 percentage point), but none of them improved the results of the coping; EPI pair significantly at the 0.1 level. The highest improvement was achieved by coping, EPI, PERMA meaning, PERMA health, and PERMA negativity, with an AUC of 0.812. In Table 3, the "Number of quintuplets" column indicates the number of quintuplets with (significant) incremental predictive power that the given factor contributed to. In this case, the PERMA negativity and PI self-control factors were represented in $21(84 \%)$ and $20(80 \%)$ groups, respectively. Only grit, PI (mobilizing and monitoring subsystems), and EQ (stress-management and mood and motivation parts) factors were contained in less than $3 \%$ of the groups with incremental predictive power. PERMA negativity participated in 13, coping in 12, and PI self-control in 11 groups out of the 14 that had significant incremental power compared to the UES.

We also investigated sextuplets, but it turned out that there were no groups out of the 38,760 possible sextuplets that carried any incremental predictive power compared to their subsets. Thus, our results showed that there is absolutely no need in measuring more than five psychological factors from an at-risk student prediction point of view.

\subsection{Summary of the Results}

We identified what groups of psychological factors had the strongest incremental predictive power over pre-enrollment achievement measures. The one-, two-, three-, fourand five-element factor groups with the highest incremental predictive power over the university entrance score together with the corresponding $p$ values (their AUC scores compared to the AUC of the UES) are shown in Table 5. We can observe that, with an appropriately chosen set of psychological factors, the incremental predictive power over pre-enrollment achievement measures was very significant. Using five factors, the AUC increased by 7.5 percentage points, from 0.737 to 0.812 .

Our aim was to identify a small set of psychological factors that had significant incremental predictive power over pre-enrollment achievement measures on academic performance. We showed that by measuring only two additional factors (coping, EPI) we could have a substantial increase in predictive performance. Moreover, in total, PERMA negativity and PI self-control seemed to be important factors to increase the predictive power. Our results suggest that it is worth measuring these factors (especially coping and EPI) at the time of enrollment. By using these attributes together with the pre-enrollment 
achievement measures, we can build a more complex model to better identify students at risk of academic failure.

Table 5. The best performing singleton, pair, triplet, quadruplet, and quintuplets together with their AUC and the corresponding $p$ values. (University entrance score is always incorporated in the models).

\begin{tabular}{ccc}
\hline Factor Groups & $\begin{array}{c}\text { AUC } \\
\text { (with UES) }\end{array}$ & $p$ Value \\
\hline only university entrance score (UES) & 0.737 & - \\
UES + coping & 0.778 & 0.0986 \\
UES + coping, EPI & 0.806 & 0.0104 \\
UES + coping, EPI, PERMA health & 0.810 & 0.0073 \\
UES + coping, EPI, PERMA positivity, PERMA negativity & 0.810 & 0.0075 \\
UES + coping, EPI, PERMA meaning, PERMA health, & 0.812 & 0.0070 \\
PERMA negativity & & \\
\hline
\end{tabular}

\section{Discussion}

We can conclude that positive psychological factors have incremental predictive validity over pre-enrollment achievement measures on university performance. It means that the right set of psychological attributes can increase the predictive power of preenrollment achievement on academic success. Results concerning the roles of positive psychological factors and personality traits clarify this interrelation (on how these factors become important at university).

In accordance with the former psychological literature [10,12-17,19,23,48], an important factor with a high incremental predictive power is EPI, a stable personality trait. On the other hand, the factor that proved to be the most important was a positive psychological factor, namely coping. The transition to university is clearly a significant life change [32], the new atmosphere and unfamiliar forms of learning may be very stressful. These stressful situations need to be learned, to be handled as much as possible so that first-year students will find it easier to overcome both general stressful situations caused by the transition to higher education, and special situations that can be caused by accountability. It explains why coping has an outstanding incremental predictive power over high school results on university performance. Students with better coping skills can manage their studies better while students with weaker stress management skills are at-risk of dropping out of university.

This result is strengthened by the psychological immunity self-regulating subsystem, which focuses on practical stress-management and perseverance during long-term coping. This subsystem includes synchronicity, impulse control, emotion control, and irritability control. These skills are learned skills and can be developed with conscious effort. At the beginning of the university years, this kind of self-control helps students to get along alone without parents or high school friends in a new environment. Control is also the basis of coping and the key component of emotional intelligence. This finding is consistent with former literature $[35,36,66]$, but shows a new aspect, i.e., the umbrella term of psychological immunity is a valid concept for the holistic description of university students' stress-management and coping skills, and it is worth using in studies. Psychological immunity is a complex phenomenon that correlates with many positive psychological source competencies; they have convergent validity when they are analyzed together, but psychological immunity seems to be suitable to be used independently.

Our findings partly clarify the former debate on the relation of EI and success [24,28-35]. One of the emotional intelligence factors stood out in the prediction of performance, namely the adaptation part, which accounted for $12.5 \%$ of all improvement factor groups and $26.8 \%$ of groups with significant improvement compared to the UES. The adaptation part of EI includes reality-testing, flexibility, and problem-solving; these factors can be the basis of stress management and are key to managing the ever-changing social environment. 
The PERMA health factor is related to physical health and that is an important part of general well-being [42]. Health is the basis of accomplishment; a subjective feeling of being healthy can be a buffer for academic stress, and help (by being perseverant) in stressful situations. Other important PERMA factors include positive and negative emotions, which show the tendency to feel positive or negative emotions [42]. This result shows that emotions are part of the daily lives of students, and can facilitate or inhibit performance. Both tendencies have incremental predictive power, and that is why we can conclude that affectivity is also a key point by assessing student vulnerability to drop-out.

Overall, the factors mentioned so far are important because good self-positioning, recognizing, and dealing with problems on time, as well as a positive attitude toward challenges, will help students to succeed during university studies. We can conclude that the measurement of positive psychological factors increases the predictive power of pre-enrollment achievement measures for university academic performance. Thus, coping, psychological immunity, emotional intelligence, and positive source competencies collected in the PERMA-model are appropriate factors that carry incremental predictive power, and an appropriate set of psychological factors can significantly increase the predictive power of the university entrance score. The combination of coping, EPI, PERMA health, together with pre-enrollment achievement measures, can predict student performance (measured by a binary variable) with an AUC of 0.81 .

Our result suggests that if we aim to build a model to identify students at risk of academic failure with high predictive power, we should use complex and holistic models, including pre-enrollment achievement, stable personality factors, and positive psychological competencies. Our results show that combining hard data, such as pre-enrollment achievement and human attributes, such as personality traits and positive psychological competencies, can increase the predictive power of the model. It seems to be possible to build holistic predictive models already at the time of enrolment if we measure the afore-mentioned psychological factors using suitable questionnaires. In Table 6, we show how many items the predictive questionnaire should contain and how long it takes to complete the survey.

Table 6. The instruments of the predictive model.

\begin{tabular}{cccc}
\hline Model & List of Instruments & Number of Items & $\begin{array}{c}\text { Completion Time (in } \\
\text { Minutes, } \\
\text { Approximately) }\end{array}$ \\
\hline one-factor model & coping & 80 & 20 \\
\hline two-factor model & coping, EPI & $80+58$ & 35 \\
\hline three-factor model & $\begin{array}{c}\text { coping, EPI, PERMA } \\
\text { health }\end{array}$ & $80+58+3$ \\
\hline four-factor model & $\begin{array}{c}\text { coping, EPI, PERMA } \\
\text { positivity and } \\
\text { negativity }\end{array}$ & $80+58+3+3$ & 45 \\
\hline five-factor model & $\begin{array}{c}\text { coping, EPI, PERMA } \\
\text { meaning, health and } \\
\text { negativity }\end{array}$ & $80+58+3+3+3$ & $100-120$ \\
\hline $\begin{array}{c}\text { Original positive } \\
\text { psychological } \\
\text { assessment battery }\end{array}$ & $\begin{array}{c}\text { emotional } \\
\text { intelligence, coping, } \\
\text { psychological } \\
\text { immunity, grit, } \\
\text { PERMA and EPI }\end{array}$ & $121+80+80+8+23$ \\
\hline
\end{tabular}

With the help of such models, at-risk students can be identified should and more efficiently. Moreover, our research showed that stress management skills, PERMA factors, and emotional intelligence have high predictive power. An additional advantage is that these competencies and skills can be effectively developed with targeted programs [67-71]; 
thus, appropriate psychological training can prevent students from dropping out. Moreover, providing information on efficient tools of stress management and offering student success courses dedicated to the acquisition of coping skills, addressing the management of emotions, and well-being, can also help at-risk students succeed [72,73].

Based on our research, a more efficient prediction model can be built to identify students at risk of academic failure at the time of enrollment. Besides pre-enrollment achievement measures, we recommend measuring some psychological factors of the students. Collecting psychological data requires filling out questionnaires that can be time-consuming and difficult to organize. Therefore, we identified what psychological factors are the most rewarding to measure in $20-45 \mathrm{~min}$. We also highlighted that measuring only one or two psychological factors has significant incremental predictive power. Moreover, using smartphone applications for measuring the psychological factors may make it easier for the students and higher education institutes. Using a more efficient tool for identifying at-risk students, educational decision-makers can also design more effective intervention programs and help students succeed in their university studies. This approach also improves the service quality of higher education, which is important for the digital generations.

\section{Limitations, Future Research Directions, and Implications}

These findings highlight the need for further research to explore the relationship between emotion-related positive psychological soft skills and academic performance. Given that the present study was limited to a homogenous sample of business and economics students, one cannot generalize the findings to other contexts, but it is worth extending the sample to other fields of higher education.

Author Contributions: Conceptualization, data curation, investigation, methodology, resources, writing - original draft preparation, review and editing-B.S.; formal analysis, methodology, software, visualization-N.S.; conceptualization, writing-review and editing-R.M. All authors have read and agreed to the published version of the manuscript.

Funding: The research reported in this paper and carried out at the Budapest University of Technology and Economics was supported by the National Research Development and Innovation Fund, based on the charter of bolster, issued by the National Research Development and Innovation Office, under the auspices of the Ministry for Innovation and Technology.

Institutional Review Board Statement: The study was conducted according to the guidelines of the Hungarian Committee of Psychological Research and approved by the Ethics Committee (approval code: 81 and 2 May, 2018).

Informed Consent Statement: Informed consent was obtained from all subjects involved in the study.

Data Availability Statement: The data presented in this study are available on request from the corresponding author. The data are not publicly available due to GDPR reasons.

Acknowledgments: We are grateful for the kind support from Ildikó Takács, Mihály Szabó, and Marcell Nagy.

Conflicts of Interest: The authors declare no conflict of interest.

\section{References}

1. Kumar, M.; Singh, A.; Handa, D. Literature Survey on Educational Dropout Prediction. Int. J. Educ. Manag. Eng. 2017, 7, 8-19. [CrossRef]

2. Alyahyan, E.; Düştegör, D. Predicting academic success in higher education: Literature review and best practices. Int. J. Educ. Technol. High. Educ. 2020, 17, 1-21. [CrossRef]

3. Rastrollo-Guerrero, J.L.; Gómez-Pulido, J.A.; Durán-Domínguez, A. Analyzing and Predicting Students' Performance by Means of Machine Learning: A Review. Appl. Sci. 2020, 10, 1042. [CrossRef]

4. Von Hippel, P.T.; Hofflinger, A. The data revolution comes to higher education: Identifying students at risk of dropout in Chile. J. High. Educ. Policy Manag. 2020, 1-22. [CrossRef]

5. Ranjeeth, S.; Latchoumi, T.; Paul, P.V. A Survey on Predictive Models of Learning Analytics. Proc. Comput. Sci. 2020, 167, 37-46. [CrossRef] 
6. Nagy, M.; Molontay, R. Predicting Dropout in Higher Education Based on Secondary School Performance. In Proceedings of the 2018 IEEE 22nd International Conference on Intelligent Engineering Systems (INES), Las Palmas de Gran Canaria, Spain, 21-23 June 2018; pp. 389-394.

7. Schneider, M.; Preckel, F. Variables associated with achievement in higher education: A systematic review of meta-analyses. Psychol. Bull. 2017, 143, 565-600. [CrossRef] [PubMed]

8. Zhou, K. Non-cognitive skills: Potential candidates for global measurement. Eur. J. Educ. 2017, 52, 487-497. [CrossRef]

9. Khan, Z.N. Cognitive and Non-Cognitive Characteristics as Determinants of Success in Professional Courses at Undergraduate Stage. J. Soc. Sci. 2009, 5, 212-215. [CrossRef]

10. Chamorro-Premuzic, T.; Furnham, A. Personality and Intellectual Competence. In Personality and Intellectual Competence; Routledge: New York, NY, USA, 2014.

11. O'Connor, M.C.; Paunonen, S.V. Big Five personality predictors of post-secondary academic performance. Pers. Individ. Differ. 2007, 43, 971-990. [CrossRef]

12. Poropat, A.E. A meta-analysis of the five-factor model of personality and academic performance. Psychol. Bull. 2009, 135, 322-338. [CrossRef] [PubMed]

13. Richardson, M.; Abraham, C.; Bond, R. Psychological correlates of university students' academic performance: A systematic review and meta-analysis. Psychol. Bull. 2012, 138, 353-387. [CrossRef] [PubMed]

14. Ninrutsirikun, U.; Imai, H.; Watanapa, B.; Arpnikanondt, C. Principal Component Clustered Factors for Determining Study Performance in Computer Programming Class. Wirel. Pers. Commun. 2020, 12, 1-20. [CrossRef]

15. Busato, V.V.; Prins, F.J.; Elshout, J.J.; Hamaker, C. Intellectual ability, learning style, personality, achievement motivation and academic success of psychology students in higher education. Pers. Individ. Differ. 2000, 29, 1057-1068. [CrossRef]

16. Rothstein, M.G.; Paunonen, S.V.; Rush, J.C.; King, G.A. Personality and cognitive ability predictors of performance in graduate business school. J. Educ. Psychol. 1994, 86, 516-530. [CrossRef]

17. Dur, K. Study of impact of personality traits on academic performance of management students. J. Organ. Hum. Behav. 2018, 7, 43-56.

18. Potgieter, I.; Coetzee, M. Employability attributes and personality preferences of postgraduate business management students. SA J. Ind. Psychol. 2013, 39, 10. [CrossRef]

19. Eysenck, H.J.; Eysenck, M.W. Personality and Individual Differences; Springer International Publishing: New York, NY, USA, 1985.

20. Chamorro-Premuzic, T.; Furnham, A. Personality predicts academic performance: Evidence from two longitudinal university samples. J. Res. Pers. 2003, 37, 319-338. [CrossRef]

21. Ridgell, S.D.; Lounsbury, J.W. Predicting academic success: General intelligence, 'Big Five' personality traits, and work drive. Coll. Stud. J. 2004, 38, 607-619.

22. Eysenck, H. Dimensions of personality: 16, 5 or 3?-Criteria for a taxonomic paradigm. Pers. Individ. Differ. 1991, 12, 773-790. [CrossRef]

23. Eysenck, H. Four ways five factors are not basic. Pers. Individ. Differ. 1992, 13, 667-673. [CrossRef]

24. Kappe, R.; Van Der Flier, H. Predicting academic success in higher education: What's more important than being smart? Eur. J. Psychol. Educ. 2012, 27, 605-619. [CrossRef]

25. Sarbin, T.R.; McClelland, D.C.; Atkinson, J.W.; Clark, R.A.; Lowell, E.L. The Achievement Motive. Am. J. Psychol. 1955, 68, 686. [CrossRef]

26. Schunk, D.H.; Pintrich, P.R.; Meece, J.L. Motivation in Education: Theory, Research, and Applications, 3rd ed.; Pearson/Merrill Prentice Hall: Upper Saddle River, NJ, USA, 2008.

27. Bar-On, R. Emotional Intelligence: An Integral Part of Positive Psychology. S. Afr. J. Psychol. 2010, 40, 54-62. [CrossRef]

28. Ahmed, Z.; Asim, M.; Pellitteri, J. Emotional intelligence predicts academic achievement in Pakistani management students. Int. J. Manag. Educ. 2019, 17, 286-293. [CrossRef]

29. Billings, C.E.; Downey, L.A.; Lomas, J.E.; Lloyd, J.; Stough, C. Emotional Intelligence and scholastic achievement in pre-adolescent children. Pers. Individ. Differ. 2014, 65, 14-18. [CrossRef]

30. Reyes, M.R.; Brackett, M.A.; Rivers, S.E.; White, M.; Salovey, P. Classroom emotional climate, student engagement, and academic achievement. J. Educ. Psychol. 2012, 104, 700-712. [CrossRef]

31. Costa, A.C.; Faria, L. The impact of Emotional Intelligence on academic achievement: A longitudinal study in Portuguese secondary school. Learn. Individ. Differ. 2015, 37, 38-47. [CrossRef]

32. Parker, J.D.; Summerfeldt, L.J.; Hogan, M.J.; Majeski, S.A. Emotional intelligence and academic success: Examining the transition from high school to university. Pers. Individ. Differ. 2004, 36, 163-172. [CrossRef]

33. Labby, S.; Lunenburg, F.C.; Slate, J.R. Emotional Intelligence and Academic Success: A Conceptual Analysis for Educational Leaders. Int. J. Educ. Leadersh. Prep. 2012, 7, 1-11. Available online: http://files.eric.ed.gov/fulltext/EJ971568.pdf (accessed on 2 November 2019).

34. Sharon, D.; Greenberg, K. Does the level of emotional intelligence affect the degree of success in nursing studies? Nurse Educ. Today 2018, 64, 21-26. [CrossRef]

35. Saklofske, D.H.; Austin, E.J.; Mastoras, S.M.; Beaton, L.; Osborne, S.E. Relationships of personality, affect, emotional intelligence and coping with student stress and academic success: Different patterns of association for stress and success. Learn. Individ. Differ. 2012, 22, 251-257. [CrossRef] 
36. Mac Cann, C.; Lipnevich, A.A.; Burrus, J.; Roberts, R.D. The best years of our lives? Coping with stress predicts school grades, life satisfaction, and feelings about high school. Learn. Individ. Differ. 2012, 22, 235-241. [CrossRef]

37. Duckworth, A.L.; Peterson, C.; Matthews, M.D.; Kelly, D.R. Grit: Perseverance and passion for long-term goals. J. Pers. Soc. Psychol. 2007, 92, 1087-1101. [CrossRef]

38. Rimfeld, K.; Kovas, Y.; Dale, P.S.; Plomin, R. True grit and genetics: Predicting academic achievement from personality. J. Pers. Soc. Psychol. 2016, 111, 780-789. [CrossRef] [PubMed]

39. Duckworth, A.L.; Gross, J.J. Self-Control and Grit. Curr. Dir. Psychol. Sci. 2014, 23, 319-325. [CrossRef] [PubMed]

40. Oláh, A. Health protective and health-promoting resources in personality: A framework for the measurement of the psychological immune system. In Positive Psychology Meeting, Quality of Life Research Center; Claremont Graduate University: Claremont, CA, USA, 2000.

41. Seligman, M.E.P. Flourish: A Visionary New Understanding of Happiness and Well-Being; Free Press: New York, NY, USA, 2011.

42. Butler, J.; Kern, M.L. The PERMA-Profiler: A brief multidimensional measure of flourishing. Int. J. Wellbeing 2016, 6, 1-48. [CrossRef]

43. Lyubomirsky, S.; King, L.; Diener, E. The Benefits of Frequent Positive Affect: Does Happiness Lead to Success? Psychol. Bull. 2005, 131, 803-855. [CrossRef] [PubMed]

44. Kern, M.L.; Waters, L.E.; Adler, A.; White, M.A. A multidimensional approach to measuring well-being in students: Application of the PERMA framework. J. Posit. Psychol. 2015, 10, 262-271. [CrossRef]

45. Dewitz, S.J.; Woolsey, M.L.; Walsh, W.B. College Student Retention: An Exploration of the Relationship Between Self-Efficacy Beliefs and Purpose in Life Among College Students. J. Coll. Stud. Dev. 2009, 50, 19-34. [CrossRef]

46. Trigwell, K.; Ellis, R.A.; Han, F. Relations between students' approaches to learning, experienced emotions and outcomes of learning. Stud. High. Educ. 2012, 37, 811-824. [CrossRef]

47. Tansey, T.N.; Smedema, S.; Umucu, E.; Iwanaga, K.; Wu, J.-R.; Cardoso, E.D.S.; Strauser, D. Assessing College Life Adjustment of Students with Disabilities: Application of the PERMA Framework. Rehabil. Couns. Bull. 2017, 61, 131-142. [CrossRef]

48. Bergold, S.; Steinmayr, R. Personality and Intelligence Interact in the Prediction of Academic Achievement. J. Intell. 2018, 6, 27. [CrossRef]

49. Eysenck, H.J.; Eysenck, S.B.G. Manual of the Eysenck Personality Inventory; University of London Press: London, UK, 1964.

50. Eysenck, H.J.; Eysenck, S.B.G. Manual of the Eysenck Personality Questionnaire (Junior and Adult); Hodder \& Stoughton: London, UK, 1975.

51. Eysenck, H.J.; Eysenck, S.B.G. Manual of the Eysenck Personality Scales; Hodder \& Stoughton: London, UK, 1991.

52. Miles, J.; Hempel, S. The Eysenck Personality Scales: The Eysenck Personality Questionnaire-Revised (EPQ-R) and the Eysenck Personality Profiler (EPP). In Comprehensive Handbook of Psychological Assessment: Personality Assessment; Hilsenroth, M.J., Segal, D.L., Eds.; Jon Wiley \& Sons: Hoboken, NJ, USA, 2003; Volume 2, pp. 99-107.

53. Bar-On, R. The Emotional Quotient Inventory (EQ-i): A Test of Emotional Intelligence; Multi-Health Systems, Inc.: Toronto, ON, Canada, 1997.

54. Bar-On, R. The Emotional Quotient Inventory (EQ-i): Technical Manual; Multi-Health Systems, Inc.: Toronto, ON, Canada, 1997.

55. Bar-On, R. The Bar-On Emotional Quotient Inventory (EQ-i): Rationale, description and psychometric properties. In Measuring Emotional Intelligence: Common Ground and Controversy; Geher, G., Ed.; Hauppauge, Nova Science: New York, NY, USA, 2004.

56. Bar-On, R. The Bar-On model of emotional-social intelligence (ESI). Psicothema 2006, 18, 13-25.

57. Duckworth, A.L.; Quinn, P.D. Development and Validation of the Short Grit Scale (Grit-S). J. Pers. Assess. 2009, 91, 166-174. [CrossRef] [PubMed]

58. Oláh, A. Érzelmek, Megküzdés és Optimális Élmény; Trefort Kiadó: Budapest, Hungary, 2005.

59. Oláh, A. Coping strategies among adolescents: A cross-cultural study. J. Adolesc. 1995, 18, 491-512. [CrossRef]

60. Oláh, A. Positive Traits: Flow and Psychological Immunity. In Proceedings of the First International Positive Psychology Summit, Washington, DC, USA, 3-6 October 2002.

61. Oláh, A. Psychological immunity: A new concept in coping with stress. Appl. Psychol. Hung. 2004, 56, 149-189.

62. Nagy, M.; Molontay, R. Comprehensive analysis of the predictive validity of the university entrance score in Hungary. Assess. Evaluation High. Educ. 2021, 1-19. [CrossRef]

63. Friedman, J.; Hastie, T.; Tibshirani, R. The Elements of Statistical Learning; Springer Series in Statistics: New York, NY, USA, 2001.

64. Vivo, J.-M.; Franco, M. How does one assess the accuracy of academic success predictors? ROC analysis applied to university entrance factors. Int. J. Math. Educ. Sci. Technol. 2008, 39, 325-340. [CrossRef]

65. Hanley, J.A.; McNeil, B.J. The meaning and use of the area under a receiver operating characteristic (ROC) curve. Radiology 1982, 143, 29-36. [CrossRef]

66. Hand, D.J. Measuring classifier performance: A coherent alternative to the area under the ROC curve. Mach. Learn. 2009, 77, 103-123. [CrossRef]

67. MacCann, C.; Fogarty, G.J.; Zeidner, M.; Roberts, R.D. Coping mediates the relationship between emotional intelligence (EI) and academic achievement. Contemp. Educ. Psychol. 2011, 36, 60-70. [CrossRef]

68. Bonneville-Roussy, A.; Evans, P.; Verner-Filion, J.; Vallerand, R.J.; Bouffard, T. Motivation and coping with the stress of assessment: Gender differences in outcomes for university students. Contemp. Educ. Psychol. 2017, 48, 28-42. [CrossRef] 
69. Crego, A.; Carrillo-Diaz, M.; Armfield, J.M.; Romero, M. Stress and Academic Performance in Dental Students: The Role of Coping Strategies and Examination-Related Self-Efficacy. J. Dent. Educ. 2016, 80, 165-172. [CrossRef]

70. Gallego, J.; Aguilar-Parra, J.M.; Cangas, A.J.; Rosado, A.; Langer, Á.I. Effect of Mind/Body Interventions on Levels of Anxiety, Stress and Depression Among Future Primary School Teacher: A Controlled Study. Rev. Psicodidáctica 2015, 21, 87-101. [CrossRef]

71. Morosanu, L.; Handley, K.; O'Donovan, B. Seeking support: Researching first-year students' experiences of coping with academic life. High. Educ. Res. Dev. 2010, 29, 665-678. [CrossRef]

72. Kassymova, K.; Kosherbayeva, N.; Sangilbayev, S.; Schachl, H. Stress management techniques for students. In Proceedings of the International Conference on the Theory and Practice of Personality Formation in Modern Society (ICTPPFMS 2018), Yurga, Russia, 20-22 September 2018.

73. Bowering, E.R.; Mills, J.; Merritt, A. Learning How to Learn: A Student Success Course for at Risk Students. Can. J. Scholarsh. Teach. Learn. 2017, 8, 1-16. [CrossRef] 